\title{
Inocência: o livro de Taunay e o filme de Walter Lima Júnior
}

Cesar A. Zamberlan'

1. Doutorando em Estudos Comparados de Literaturas de Língua Portuguesa pela FFLCH USP. Professor da Faculdade de Letras, Artes, Comunicação e Ciências da Educação da Universidade São Judas Tadeu (SP), pesquisador do CEIFEC (Grupo de Estudos sobre Itinerários de Formação em Educação e Cultura) da FE USP, editor da Revista Interlúdio, www.revistainterludio.com.br e membro da Associação Brasileira dos Críticos de Cinema.. E-mail: cesarzamberlan@uol.com.br 


\section{Resumo}

A proposta deste artigo é trabalhar a adaptação do livro Inocência (1872), de Visconde de Taunay, para o cinema, por meio da análise do filme homônimo, Inocência (1982), de Walter Lima Júnior. O artigo busca no filme elementos que denotem uma (re)leitura do texto fonte a partir da criação de uma nova significação, seja pela busca de um equivalente fílmico que contemple o significado literário, seja pelo acréscimo, redução ou pelos deslocamentos de personagens ou situações da trama original.

\section{Palavras-chave}

Taunay, literatura, adaptação

\section{Abstract}

The idea of this article is to analyse the adaptation of Visconde deTaunay's novel Inocência(1872) to the screen, more specifically the eponymous film directed by Walter Lima Junior in 1982. The article seeks in the film elements that indicate a (re)interpretation of the novel and its new meanings, either in the search for afilm equivalent that contemplates the literary meaning, and/or by the addition, reduction or displacement of characters or situations from the original plot.

\section{Keywords}


temáticas

livres

A adaptação de uma obra literária para o cinema busca, na realidade do livro, a base para a reconstrução de um novo mundo a partir de elementos de criação inerentes ao processo audiovisual. É, sempre, portanto, uma nova leitura. Leitura que, guardadas as diferenças na relação de invenção e composição a partir do dispositivo fílmico, é semelhante ao processo de construção do texto literário em seu liame com a realidade observada e ou vivida. Nesse sentido, da mesma forma que é impossível retratar a realidade de maneira fiel, também seria impossível pensar em fidelidade ao texto literário. Pois, assim como a realidade tocada pelo olho humano (bem como pelos outros sentidos) ganha, no experimentar o mundo, por meio de uma série de processos de significação, nova forma; o mesmo ocorre com o livro, seja no processo de leitura individual, seja no processo de leitura e reconstrução desse universo pelo cineasta e por sua equipe.

Portanto, o que se busca mostrar são os dois processos de composição - livro e filme - com seus pontos de conjunção e disjunção estéticas ou de conteúdo, para, no final deste artigo, trabalhar as leituras de mundo que escritor e cineasta fazem visando significar suas épocas.

\section{O livro}

Inocência de Visconde de Taunay é uma obra tardia dentro do Romantismo e talvez por isso ${ }^{2}$ e pelo senso de observação do seu autor ${ }^{3}$ tenha se tornado uma

2. Penso aqui no acúmulo de experiências literárias do período, no aproveitamento dos erros e acertos da experiência dos escritores anteriores, sobretudo de Alencar e Macedo, bem como na observação dos escritores estrangeiros. Em Formação da literatura brasileira, Antonio Candido (1997: 282) justifica até mesmo por que não se deve colocar o autor fora da escola romântica e usa o termo "sincretismo" para descrever essa bagagem intelectual. Candido finaliza o seu estudo dizendo que "a maneira de aprender e interpretar os atos e sentimentos - esta permanece no universo do Romantismo".

3. Visconde de Taunay era militar, viajava pelo sertão e era profundo conhecedor de música e artes plásticas. 
das obras mais bem acabadas do período. ${ }^{4}$ Consegue conciliar, a partir do que é regional, aspectos do Romantismo e do Realismo que lhe sucederia.

Taunay reconhecia o talento dos seus antecessores, mas criticava Alencar por certo artificialismo, por desconhecer a natureza brasileira. ${ }^{5} \mathrm{E}$, diferente do autor de Iracema, criava suas histórias com base na observação in loco dos acontecimentos e das personagens, trabalhando a relação do homem com o espaço físico por um modelo observacional rigoroso que depois seria usado de modo semelhante por Euclides da Cunha e Guimarães Rosa, entre outros.

Tal método, ao proclamar uma maior fidelidade ao real, não elimina, no entanto, a fabulação. Pelo contrário, com essa experiência e os tipos descobertos por ela, Taunay busca engendrar personagens não só mais verossímeis como talvez ainda mais marcantes quando transferidos ao campo da ficção. A personagem Inocência é inspirada em Jacinta, uma jovem de beleza extraordinária que era, porém, na vida real, leprosa; o anão Tico era barqueiro no Rio Sucuriú; Pereira, o pai de Inocência e o curandeiro Cirino, que no livro será o par romântico de Inocência, também foram modelados ficcionalmente a partir das observações em campo de Taunay, pessoas com as quais o escritor conviveu nas suas viagens.

Em Formação da literatura brasileira, Antonio Candido (1997: 279), ao analisar esse processo de criação, estabelece uma interessante relação entre fidelidade, realidade e invenção criadora:

Há tipos copiados fielmente, outros elaborados a partir da sugestão inicial, outros compostos com elementos tomados a mais de um modelo. E isso denota maior complicação do que supunha o próprio Taunay, ao proclamar sua fidelidade ao real porque, em qualquer arte, desde que apareça uma certa tensão criadora, mais importantes que as sugestões da vida (acessíveis a

4. "Não há nada que supere Inocência em simplicidade e bom gosto, méritos que o público logo lhe reconheceu, esgotando sucessivamente mais de trinta edições sem falar nas que, já no século passado, se fizeram em quase todas as línguas cultas." (BOSI, 1994: 145)

5. Segundo Taunay (apud CANDIDO, 1997: 277-278), Alencar descrevia a natureza "do fundo do seu gabinete, lembrando-se muito mais do que lera do que aquilo que vira com os próprios olhos". 
todos) tornam-se a invenção e a deformação, devidas não só às capacidades intelectuais de composição, como às possibilidades afetivas, à memória profunda, ao dinamismo recôndito do inconsciente.

temáticas

livres

A análise de Antonio Candido traz implicações interessantes à leitura de Inocência ao contrapor, no processo de composição de Taunay, a relação entre a observação mais fiel aos dados, algo típico da ciência, e a observação relacionada ao fazer artístico, na qual o processo de criação encontra maior liberdade. Achar-se em meio a essas duas possibilidades não só parece ser o grande desafio que Taunay se impõe em Inocência, como parece, também e em parte, uma das questões do livro.

Taunay abre o livro com uma detalhada exposição do sertão, o descreve geograficamente - paisagem, clima, flora, fauna, regime de queimada e de chuvas, o transbordar da vida - para, nesse cenário, instalar o seu personagem principal, até aqui um homem sem nome e que só será nomeado capítulos depois. Passa então a descrever a relação desse homem (não o personagem, mas o tipo, sertanejo) com o meio, no momento em que ele deixa suas andanças e procura uma esposa e o sossego da família a ser constituída. No capítulo seguinte, Taunay faz a descrição do viajante e, aí sim, o personifica. Isso ocorre no momento em que o personagem encontra, ou melhor, é encontrado por Pereira, o fazendeiro que foi à vila procurar por remédio para sua filha Inocência. A partir desse encontro - o pai de Inocência se emparelha ao viajante sem saber que ele é um "doutor” -, a estratégia narrativa se altera: do ponto de vista único do narrador onisciente que expõe uma verdade, quase cientifica, sobre o local e os personagens, temos, por meio do diálogo entre ambos, a revelação sobre os personagens, inclusive seus nomes e uma breve biografia.

Passamos a ter, então, não só a observação do narrador, mas uma outra camada de observação: a dos personagens, sua impressão de mundo revelada pelo narrador por meio dos diálogos que, se num primeiro momento servem apenas como forma de apresentação, logo serão a expressão da observação 
de tipos bem distintos. E os diálogos - nisso consiste uma enorme qualidade e avanço de Taunay - são elaborados a partir da fala real de tipos, no caso, o fazendeiro, o curandeiro viajante, o cientista alemão, a menina reclusa, o sertanejo autêntico, entre outros.

Com a amenização do olhar direto do escritor para as personagens e para o cenário, passamos a ter, dado pelo autor, mas de forma indireta, o olhar das personagens a partir do momento em que chegam à casa de Pereira. Agora o olhar científico e o artístico fundem-se. Apenas em um momento, o autor voltará a se posicionar como portador de uma verdade sobre o contexto que constrói; ${ }^{6}$ no mais, trabalhará a narração pelo olhar/ observação das personagens e pelo tipo que representam.

Mas não é só na construção do livro que existe essa oposição entre um olhar mais cientificista e uma observação de cunho mais empírico do saber popular e consagrado pela natureza. Se pensarmos nas personagens, temos também uma cisão de natureza similar. Cirino, que chega à casa de Pereira para tratar Inocência, não é de fato um médico formado, mas um curandeiro. ${ }^{7}$ Conhece alguns dos segredos da medicina pela observação e por experiências que realizou nas suas andanças, mas não é "doutor". O homem da ciência é Meyer, o naturalista alemão, um zoólogo que trabalha para o governo de seu país. Por sua vez, Pereira, o anfitrião de ambos, como fica claro quando Meyer mostra a carta de apresentação escrita por seu irmão, mal sabe ler e escrever.

6. A exceção ocorre quando o narrador comenta uma fala de Pereira dizendo que mulheres em casa são coisas de meter medo, são redomas de vidro que tudo podem quebrar. Nesse momento, o narrador, como um cientista, volta a afirmar uma verdade, um diagnóstico: "Esta opinião injuriosa sobre as mulheres é em geral corrente em nossos sertões e traz como consequência imediata e prática, além da rigorosa clausura em que são mantidas, não só o casamento convencionado entre parentes muito chegados para filhos de menor idade, mas sobretudo os numerosos crimes cometidos, mal se suspeita a possibilidade de qualquer intriga amorosa entre a pessoa da família e algum estranho" (TAUNAY, 2009: 45).

7. "Curandeiro, simples curandeiro, ia por toda a parte granjeando o tratamento de doutor." (TAUNAY, 2009: 36) 
Pereira, no entanto, reconhece o saber e admira os doutores, consciente que é

ano I número I

temáticas

livres da sua posição no mundo e do seu isolamento. Sabe também o perigo que esse olhar mais aberto para o mundo representa, sobretudo, em relação a Inocência, prometida a Manecão, homem do seu universo.

Tornando mais clara tal relação, é preciso lembrar três momentos importantes do livro. O primeiro, quando Pereira adverte Cirino em relação a Inocência e diz: "Veja só a doente e não olhe para Nocência" (TAUNAY, 2009: 46). O segundo, quando Inocência nos é apresentada por Pereira, e ele nos diz que em determinado momento da juventude ela quis conhecer os livros, mas ele rejeitou a ideia: “Aqui havia um livro de horas da minha defunta avó... Pois não é que um belo dia ela me pediu que lhe ensinasse a ler?... que ideia!" (TAUNAY, 2009: 4748). E o terceiro, depois que Inocência recusa Manecão, quando este pergunta a Pereira se ela viu alguém.

Em relação ao primeiro momento, Pereira praticamente diz a Cirino que veja a menina com olhos de cientista, e não com olhos humanos e desejosos. No segundo momento, Pereira, com medo de perder a filha para além do mundo que conhece, a fecha em sua redoma de vidro sem a possibilidade de ter um conhecimento que não seja o dado pela natureza de maneira imediata - ou seja, não mediada pelo conhecimento simbólico. E no terceiro momento, Pereira tem a certeza do contágio de Inocência com o mundo externo.

A mediação do mundo pelo saber, que assusta Pereira, marca o fim de uma era, de uma possibilidade de estar naquele espaço, acomodado pelas regras do sertão que Taunay, como homem da cidade, condenava. Podemos dizer até aqui que, da mesma forma que Taunay é um romântico tardio e se encontra no limite entre o Romantismo e o Realismo trazido por Machado de Assis, ${ }^{8}$ sua

8. O livro de Taunay é lançado no mesmo ano do primeiro romance de Machado, Ressurreição, e, no ano seguinte, 1873, Machado escreve um texto fundamental, demarcando uma nova era no Romantismo: “Instinto de nacionalidade". Quem analisa bem a questão é José Veríssimo (1963: 235), que afirma que Inocência é o primeiro livro realista no sentido estrito do termo. 
linguagem também aponta pela primeira vez para uma confluência de tempos, ao mesclar um olhar descritivo e cientifico para a paisagem a uma observação mais refinada dos personagens e do meio em que estão inseridos, sendo que a história narrada também se coloca nesse ponto limítrofe entre um mundo arcaico e um mundo novo que lhe bate à porta. ${ }^{9}$

Fechando a analise do livro, é necessário apontar outros dois aspectos: o tabuleiro, que é o centro das ações, e, nele, a posição central da personagem Inocência.

O processo de confluência a um local sede das ações é bastante claro. Tanto o leitor como os personagens de Pereira e Cirino chegam ao local que receberá depois o naturalista alemão e seu ajudante. Local onde está Inocência, que é o elemento central da narrativa, a partir do qual esta se construirá e ao redor do qual toda a ação gravitará.

No livro, a presença física, em cena, de Inocência é pequena. O pai a esconde, pois a presença da mulher é um problema, ainda mais quando bela, jovem e solteira. Mas ainda que seja pouco vista (pela lógica que ali impera, ela não deve ver nem ser vista), ela está presente no livro o tempo todo. Pereira a protege como pai zeloso, mais, talvez, para fazer valer sua identidade social naquele grupo do que por um amor incestuoso - algo que estará presente, de certo modo, na adaptação para o cinema. Cirino, quando a vê, ainda que alertado por Pereira, se apaixona perdidamente. Já o alemão se encanta por ela e torna pública a sua admiração da mesma forma como se encanta pelas belezas naturais que o país lhe apresenta. Todos olham para Inocência, mas são olhares diferentes entre si. O de Cirino é o olhar romântico; o de Meyer, o olhar estrangeiro, daquele que observa o exótico; o de Pereira, o olhar paterno da lei, ainda que arcaica. Já Manecão e Tico, por estarem inseridos

9. O livro termina com Meyer expondo sua descoberta científica na Alemanha, isso dois anos após a morte de Inocência. Ele é o único personagem do livro que termina a história de maneira "gloriosa". 
ano I número I

temáticas

livres

dentro do mesmo espaço e costume de Pereira, assumem um mesmo tipo de olhar - o olhar preservador, que prevê a manutenção daquele estado. Meyer, ainda que externe seu encantamento de maneira efusiva, é, entre todos, o que melhor lida com a beleza que lhe toca os olhos e, por externar sem medo esse encantamento, é ele que será mais vigiado e cobrado. Ao olhar só para Meyer e duvidar dele, Pereira deixa de perceber Cirino, e aí a trama se configura. Diante da impossibilidade romântica de conciliar dois mundos antagônicos (a natureza sertaneja e o saber e as leis do mundo), Cirino e Inocência só encontram uma saída para o seu amor: pedir ao padrinho dela que sirva como mediador, que se interponha junto a Pereira, como conciliador. Papel que ele pode fazer, pois Pereira lhe deve favores e dinheiro. Esse padrinho seria, numa linha do tempo - para não dizer evolutiva, pois isso parece implicar um juízo de valor -, um meio termo entre a rusticidade do sertão e as mudanças que a urbanidade e a civilização trazem àquele lugar. No entanto, nem esse expediente vai interferir no trágico desfecho do livro, pois o padrinho tarda a se decidir. Tal desfecho não só é consoante ao espírito do Romantismo vigente - se pensarmos, como lembra Antonio Candido, em Chateaubriand e no próprio Alencar de Iracema - como será consoante ao Realismo que se anunciava - se pensarmos nas leis que vigoram no sertão. O desfecho cabe nos dois esquemas e, mais que isso, denota o processo de fusão entre a observação do real e a criação artística, tal como salientou Candido em relação a Taunay. Tal dado pode ser relacionado a uma história contada pelo próprio escritor em suas memórias: Taunay conta que teria vivido um idílio com a indiazinha Antonia, comprada junto ao pai dela na região central do Brasil e com a qual teria tido momentos felizes até voltar à cidade. Abandonada, a indiazinha teria morrido. ${ }^{10}$

10. “Embelezei-me de todo por esta amável rapariga e, sem resistência, me entreguei ao sentimento forte, demasiado forte, que em mim nasceu. Passei, pois, ao seu lado dias descuidosos e bem felizes, desejando de coração que muito tempo decorresse antes que me visse constrangido a voltar às agitações do mundo, de que me achava tão separado e alheio." (apud CANDIDO, 1997: 280) 


\section{filme}

No processo de construção do romance, Taunay sabia estar escrevendo uma obra marcante dentro da literatura nacional. O mesmo não vai acontecer com Walter Lima Júnior no processo de adaptação do livro. Ele sabia que estava filmando algo estranho à sua época, e quando Humberto Mauro lhe perguntou por que filmar Inocência naquele momento, ele respondeu: "Eu adoro me imaginar fazendo um filme sobre aquilo que não existe" (MATTOS, 2002: 265).

O cineasta se referia ao amor que leva à morte, à palavra empenhada que é respeitada até as últimas consequências, e aos hábitos, tratamentos e maneiras de falar típicos do Brasil interiorano do século XIX. Lima Júnior faria o que chamou de uma "cinearqueologia de costumes". Romperia, de certa forma, com o cinema que fazia até então, ${ }^{11}$ com as influências marcantes do Cinema Novo e com o cinema de Glauber Rocha, para retomar, e dar novo corpo, a um estilo de cinema mais antigo, o cinema narrativo do próprio Humberto Mauro e de Lima Barreto - dois cineastas que lutaram para adaptar o romance e não conseguiram. ${ }^{12}$ Walter Lima Júnior queria fazer justiça aos dois adaptando o romance de Taunay e, mais do que isso, fazendo-o a partir do roteiro de Lima Barreto e com as indicações que Humberto Mauro passara a este, já que o projeto de adaptação de Mauro não foi em frente e os direitos ao livro acabaram nas mãos de Lulu de Barros e Fernando de Barros que o filmaram, em 1949, com Maria Della Costa fazendo o papel de Inocência.

Foi, aliás, uma entrevista de Humberto Mauro, quando este completava 84 anos, que levou Walter Lima Júnior definitivamente à adaptação. ${ }^{13}$ Mauro disse

11. Walter define o cinema da época como um "cinema obcecado pelo contemporâneo e pelo histórico" (MATTOS, 2002: 264).

12. A Adaptação de Walter Lima Júnior é a terceira adaptação do livro para o cinema. A primeira foi feita por Vittorio Capellaro em 1915, e a segunda, já citada, por Lulu de Barros em 1949. Além destas, o livro foi adaptado para a televisão, no programa Caso especial, da TV Globo, em 1973, com a direção de Domingos Oliveira e com José Wilker e Irene Stephania no elenco.

13. Walter já pensava na adaptação no final dos anos 1950, quando confessava ler e reler o livro (MATTOS, 2002: 264). 
ano I número I

temáticas

livres

na entrevista que "Inocência era uma dívida sua para com o cinema brasileiro".

Walter Lima Júnior, sabendo do roteiro de Lima Barreto e que este, aos 76 anos, se encontrava internado como indigente em Campinas, convenceu Luís Carlos Barreto, o Barretão, a produzir o filme, e acabou comprando os direitos e o roteiro de Inocência junto a Lima Barreto. Inocência voltava a existir 110 anos após a publicação do livro.

A adaptação de Walter Lima Júnior traz, logo no início, duas imagens bastante definidoras do filme. ${ }^{14}$ Nos créditos, uma crisálida se abre e em tempo real ainda que uma luz tenha acelerado o processo - transforma-se em borboleta. Está configurada a metáfora que liga casulo a claustro e que, sugerida no romance, será bastante explorada no filme e ganhará ainda mais sentido após os créditos iniciais e com a primeira imagem de Inocência, febril e delirante na cama, sem que possamos definir se essa imagem se relaciona à maleita que acomete a personagem no início da narrativa, ou ao seu desfecho, após a morte de Cirino. A atemporalidade da imagem vai remeter a um ciclo como o da borboleta, “metáfora desse estado intermediário em que se encontra Inocência, entre o não-ser e a vida, e entre a vida e a morte" (MATTOS, 2002: 268). Outra leitura interessante e possível a partir desse início é que tudo seja um delírio de Inocência, algo bastante fora do universo do livro, mas muito citado por Walter Lima Júnior quando fala sobre o seu filme. Leitura que fará mais sentido quando concluirmos esta análise.

Voltando à relação entre filme e livro, é possível notar, logo no início do filme, a presença constante e central de Inocência. Se na obra de Taunay ela era uma ausência, uma pérola escondida, na obra de Walter Lima Júnior ela será sempre presença. Toda sugestão a ela no livro se materializa na beleza juvenil 
de Fernanda Torres e num jogo de luz que acabará compondo cada cena para manifestar diferentes estados de alma.

Nesse sentido, é bastante reveladora a dissertação de mestrado de Flávio de Mattos, A construção da mímesis na iluminação do cinema: um ensaio sobre a fotografia de Inocência, defendida na Universidade de brasília em 1996, na qual o autor, a partir da ideia de que "trabalhar a luz é uma forma de se criar além do texto, além da representação" (apud MATTOS, 2002: 272), vai decifrando como a luz opera nas cenas noturnas do filme: a oposição entre a luz quente amarela da febre e do aprisionamento e dos espaços fechados e a luz fria azul, libertadora e romântica, do espaço aberto e do luar. ${ }^{15}$

Para fazer a "cinearqueologia de costumes", Walter Lima Júnior e o fotógrafo Pedro Farkas fizeram um uso bastante poético da luz, o que implicou em alguns momentos, como lembra Carlos Alberto Mattos, uma discussão a respeito da verossimilhança ou não do foco luminoso. Isso ocorreu, por exemplo, logo no início das filmagens, na cena do delírio de Inocência. Farkas tinha planejado um tipo de iluminação, e o cineasta sugeriu outro. Farkas perguntou então ao diretor de onde viria aquela luz e Walter respondeu que aquilo não lhe interessava e que a realidade ali era poética (MATTOS, 2002: 271). O diálogo revelou a Farkas um novo caminho para a luz no filme e, daí em diante, a relação entre o que a luz revela e/ou encobre tornou-se decisiva para compor personagens e cenas.

Ainda no que tange à presença maior de Inocência em cena e à composição visual do filme, merece atenção a cena na qual Inocência se banha e é flagrada pelo pai. Graças à sua composição e luz, a cena lembra um quadro acadêmico e mais uma vez a elaboração dos planos parece ligada a uma pesquisa iconográfica

15. O cineasta David Neves também reforça esse aspecto visual da luz no filme em artigo para a revista Filme Cultura. Diz ele: “Acho que o azul é a cor predominante de Inocência. Há planos transcendentais quando essa cor esparge por certas frestas, um amarelo ouro que nos aproxima dos nichos e dos altares iluminados de nossas igrejas coloniais. É que Inocência é ave noturna, melhor seria dizer crepuscular..." (NEVES, 1984: 76). 
ano I número |

temáticas

livres

que remete às artes plásticas, tal qual ocorre na composição da paisagem que remete a quadros de Taunay, no caso o avô do escritor, bem como a Debret, Rugendas e Rubeirolles - referências citadas inclusive no roteiro de Lima Barreto. Por outro lado, a cena, que não existe no romance, além de ir ao encontro dessa presença maior da personagem no filme, insinua pelo olhar do pai uma tensão incestuosa que o livro está longe de sugerir. Longe de querer julgar a questão pela falsa base da fidelidade, ${ }^{16}$ a leitura, modernizada, de Walter Lima Júnior, propõe um novo componente e, por esse mecanismo, o fato de Pereira prometer a filha a Manecão - alguém como ele - opera como uma transferência, uma projeção. Tal operação foi abalizada pelo psicanalista Hélio Pellegrino, que acabou como consultor de Walter à época (MATTOS, 2002). Por outro lado, a relação entre ausência/sugestão e presença/deflagração na relação entre literatura e cinema ganha aqui mais um exemplo, dentro do campo de significação possível a cada linguagem na sua forma de ler e de ser leitora do mundo.

Ainda em relação à presença de Inocência no filme, é bastante interessante a opção do cineasta por não matá-la ao final da história, como ocorre no livro, deixando-a na cama em uma nova cena de transe, o que remete também à cena inicial do filme. Com a morte de Cirino, com o retorno do cientista alemão à Europa, onde anunciará a descoberta de sua nova espécie de borboleta, a Papilio inocentiae, temos, ainda que por sugestão, um retorno à estaca zero da narrativa. Temos todo um processo que gira em falso, sem que de fato aconteça um deslocamento da história.

Se, no livro, a morte de Inocência traz ao universo representado uma perda, a aniquilação daquilo que parecia ser o mais importante, no filme, ainda que exista a metáfora da borboleta que pousa na cruz onde está enterrado Cirino - imagem, aliás, sugerida a Lima Barreto por Humberto Mauro -, a morte da heroína não se concretiza.

16. Quem faz um cotejo bastante rigoroso entre livro e filme é a pesquisadora Zulmira Ribeiro Tavares em "O olho e ouvido da forma literária", artigo publicado na edição de n 44 da revista Filme Cultura, em 1984. 
Walter Lima Júnior chegou a dizer que ainda que vejamos Inocência quase morrendo no início e no final do filme, ele teria ficado com pena de matar a personagem (LIMA JÚNIOR, 1997: 172). Essa indefinição, que a coloca mais uma vez como morta-viva, é bastante significativa se pensarmos no sonambulismo a ela conferido pelo filme, estado que também, por natureza, está entre o sono e o despertar, bem como a imagem da crisálida dos créditos.

Se as indicações iniciais de filme e livro dão conta com bastante clareza dos caminhos seguidos por cineasta e escritor, as opções de ambos no desfecho das narrativas são também bastante esclarecedoras da leitura que ambos fazem de sua época por meio da narrativa que constroem. Taunay faz seu hino às ciências ${ }^{17}$ e termina o livro com a consagração de Meyer na Europa no mesmo dia em que completa dois anos a morte de Inocência. A morte é anunciada ao leitor em míseras quatro linhas finais, sendo que o autor se refere a ela como "coitadinha" (TAUNAY, 2009: 170). No filme, por sua vez, não a temos morta, tampouco a temos viva. O que existe é esse estado intermediário, esse meio do caminho. Estado de suspensão, tal qual o delírio de Brás Cubas em Machado de Assis, que parece apontar para dois pontos: a indefinição entre ser e não ser e a impossibilidade de ser ante a opressão da lei - nesse caso manifestada pelo desejo paterno e pelos costumes do sertão. Tais pontos voltarão a aparecer em A ostra e o vento, imageticamente antecipado pela cena da fuga de Inocência, capturada depois pelo pai, e pela cena final com o lençol esvoaçante.

Ao fazer um filme sobre aquilo que teoricamente não mais existia, Walter Lima Júnior acabou não só abrindo uma trilha nova em sua carreira, como pareceu reafirmar, de certa forma, aquilo que o cinema novo e outros filmes e livros seminais de outros períodos já apontavam: a impossibilidade de síntese diante da experiência de modernidade conservadora que sempre atravessou o

17. Walter Lima Júnior chegou a sugerir, no material de divulgação do filme, um trocadilho entre "Hino à Ciência" e "Inocência" (NEVES, 1984: 77). 
país. Só o cientista alemão se safa, em Inocência. Tanto é que Taunay termina seu

temáticas

livres livro com Meyer fora do país, e não há um resgate do que aconteceu a posteriori na narrativa, a não ser pelas já citadas quatro linhas sobre Inocência. No caso do filme, não temos essa ode à ciência, mas uma reelaboração poética do delírio brasileiro a partir da impossibilidade de se configurar como sujeito autônomo num universo que ainda respira a repressão e é estagnado e estagnante. Cabe lembrar que Walter Lima Júnior filma Inocência em 1983, período em que o Brasil se redemocratizava, mas vivia, ainda, cercado de incertezas. 


\section{Referências bibliográficas}

AVELLAR, José Carlos. O chão da palavra: cinema e literatura no Brasil. Rio de Janeiro: Rocco, 2007.

BOSI, Alfredo. História concisa da literatura brasileira. São Paulo: Cultrix, 1994.

CANDIDO, Antonio. Formação da literatura brasileira. Belo Horizonte: Itatiaia, 1997. 2 vol.

LIMA JÚNIOR, Walter. "Literatura mais cinema: a palavra (uma ostra?) e a imagem (um vento?)". Cinemais, n 6, julho/agosto de 1997, p. 171-180.

MATTOS, Carlos Alberto. Walter Lima Júnior Viver Cinema. Rio de Janeiro: Casa da Palavra, 2002.

NEVES, David. "Madame Butterfly”. Filme Cultura, n 43, janeiro/abril de 1984, p. 76-78.

TAUNAY, Visconde. Inocência. São Paulo: Saraiva, 2009.

TAVARES, Zulmira Ribeiro. "O olho e o ouvido da forma literária”. Filme Cultura, n 43, janeiro/abril de 1984, p. 79-86.

VERÍSSIMO, José. História da literatura brasileira. Brasília: Editora da Universidade de Brasília, 1963.

\section{Obra audiovisual}

INOCÊNCIA. Brasil. 1983. Direção e roteiro: Walter Lima Júnior. Produção: Lucy e Luis Carlos Barreto. Coprodução: Embrafilme. Fotografia e Câmera: Pedro Farkas. Música: Wagner Tiso. Montagem: Raimundo Higino. Elenco: Edson Celulari, Fernanda Torres, Sebastião Vasconcelos, Rainer Rudolph, Fernando Torres, Ricardo Zambelli, Chico Dias, Jorge Fino, Chica Xavier e Sandro Solviati. 